Review

\title{
Emerging Therapies and Future Directions in Targeting the Tumor Stroma and Immune System in the Treatment of Pancreatic Adenocarcinoma
}

\author{
Daniel H. Ahn, Ramesh K. Ramanathan and Tanios Bekaii-Saab * \\ Department of Hematology/Medical Oncology, Mayo Clinic Cancer Center, 5777 E. Mayo Blvd, Phoenix, \\ AZ 85054, USA; ahn.daniel@mayo.edu (D.H.A.); ramanathan.ramesh@mayo.edu (R.K.R.) \\ * Correspondence: bekaii-saab.tanios@mayo.edu; Tel.: +1-480-342-4800
}

Received: 24 April 2018; Accepted: 5 June 2018; Published: 11 June 2018

\begin{abstract}
Pancreatic adenocarcinoma is typically refractory to conventional treatments and associated with poor prognosis. While therapeutic advances over the past several years have improved patient outcomes, the observed benefits have been modest at best, highlighting the need for continued development of alternate treatment strategies. The tumor microenvironment has been identified as being integral to oncogenesis through its direct effect on cellular pathway communication, immune inhibition, and promoting chemo-resistance. A more in depth understanding of the biology of the disease, in addition with our ability to develop more effective novel therapies have led to ongoing studies that are investigating several promising treatment options in this disease. Herein, we highlight and review the therapeutic landscape in pancreatic adenocarcinoma.
\end{abstract}

Keywords: desmoplasia; microenvironment; pancreatic adenocarcinoma; stroma; novel targeted therapies; immunotherapy

\section{Introduction}

In the United States, pancreatic ductal adenocarcinoma (PDA) is the fourth leading cause of cancer related deaths, with a five-year survival rate of less than $10 \%$, it will become the second leading cause of cancer-related deaths in this country by 2030 [1]. In 2017, roughly 53,670 new cases of pancreas cancer were diagnosed, with approximately only $10 \%$ of patients with clearly resectable disease at presentation [1,2]. During the past decade, therapeutic advances include the approval of two chemotherapy regimens for patients with newly diagnosed metastatic PDA and the first approved chemotherapy regimen for those with treatment refractory disease [3-5]. Despite these advances, patient outcomes remain dismal where the median overall survival remains less than 12 months, underscoring the continued investigation and need for the development of novel therapies in this disease. An increased understanding of the pancreatic tumor microenvironment includes the tumor stroma and its involvement in chemotherapy resistance and immunosuppression. This has resulted in the development of novel therapies to overcome these tumor intrinsic factors. Herein, we review and highlight novel therapeutic approaches aimed at the tumor microenvironment and strategies to overcome the immunosuppression in PDA (Figure 1). 


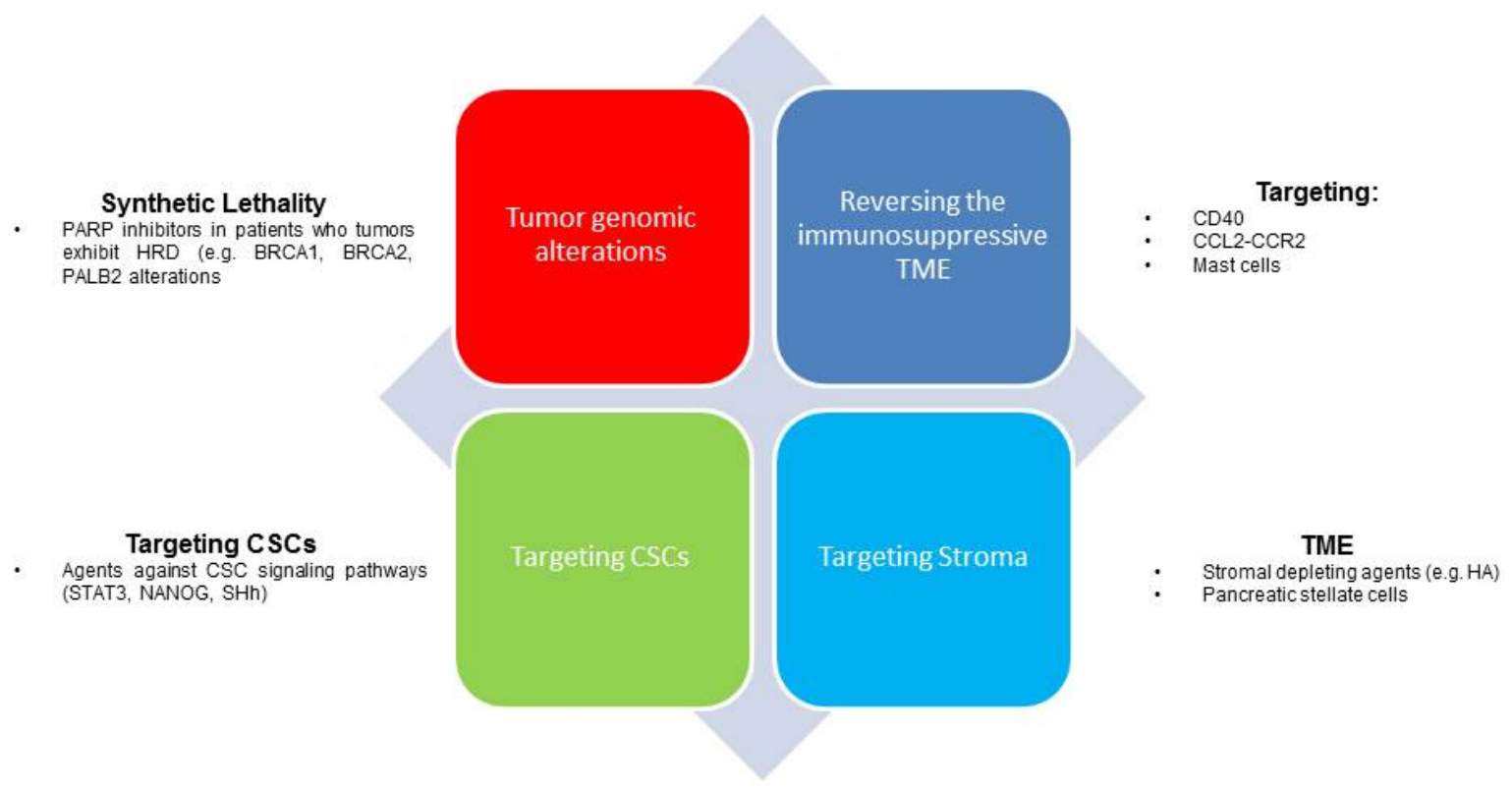

Figure 1. Treatment strategies in pancreatic adenocarcinoma. The figure provides an overview of novel treatment strategies in treatment of PDA. HRD, homologous recombinant deficiency; HA, hyaluronic acid; CSCs, cancer stem cells; SHh, Sonic Hedgehog pathway; MET, tumor microenvironment.

\section{Targeting Pancreatic Cancer Stroma}

\subsection{Tumor Stroma}

The histologic feature observed in PDA that is integral to its innate characteristic features is the tumor microenvironment (TME). TME is comprised of cellular elements and a marked desmoplastic reaction. TME is comprised of various cell types that include mesenchymal cells, which are most notably fibroblasts of various types including pancreatic stellate cells (PSCs), inflammatory associated cells, glycoasminoglycans, and the vascular endothelium [6]. PSCs are a subset of pancreatic cancer associated fibroblasts that are integral in tumor-stromal interactions and the development and maintenance of the desmoplasia. PSCs are resident cells of the pancreas that remain in a quiescent state and function to regulate normal tissue architecture [7]. In PDA, pancreatic cancer cells activate PSCs through various signaling (MAPK, PI3k/Akt, and JAK-STAT) pathways, inflammatory cytokines and reactive oxygen species that induce aberrant activation of PSCs [8]. Activated PSCs can produce autocrine factors (TGF $\beta 1$, PDGFR, IL-1, IL-6, etc.), which further potentiate its activity that results in the synthesis of excessive extracellular matrix (ECM) ECM proteins, secretion of growth factor and cytokines that induce pancreatic cancer cell growth and migration [9]. The overproduction of ECM contributes to the fibrotic reaction that contributes to tumor proliferation and chemotherapy resistance in PDA [10]. PSCs also induce endostatin production from pancreatic cancer cells, which contributes to intratumoral hypoxia, which serves as another mechanism for chemotherapy resistance [11]. Thus, the fibrotic and avascular microenvironment decreases effective chemotherapy delivery, which contributes to treatment resistance and tumor progression.

PSCs also help mediate the immunosuppressive TME associated with PDA. In preclinical human PDA samples demonstrated that activated PSCs reduced the $\mathrm{CD} 8^{+} \mathrm{T}$ cell migration within the tumor stroma [12]. Furthermore, further work has shown PSCs promote the differentiation of immune inhibiting myeloid-derived suppressor cells, suggesting PSC's contribute to the immunosuppressive TME observed in PDA [13]. 
Given the various roles that PSCs serve in contributing to tumor proliferation and treatment resistance in PDA, there is significant interest in various strategies aimed at targeting PSCs, which including inhibiting PSC proliferation and their conversion into an inactive quiescent state. While these strategies are intriguing, fibroblasts including PSCs play a protective role (below) and its inhibition can potentially result in PDA proliferation.

\subsection{Hyaluronic Acid}

Hyaluronic acid (HA), is one of several glycoasminoglycans that comprises the ECM and is present in normal tissue in several organs. HA is a glycoasminoglycan commonly found in the extracellular matrix and high HA content in observed across several solid tumors including pancreas cancer. In pancreas cancer, high HA content is present as high as $90 \%$ of PDA tissue and is a poor prognostic factor [14]. Chemoresistance is thought to be in part due to the ECM, where HA polymers bind and trap water molecules to alter the tissue architecture into a mechanical barricade that impedes effective chemotherapy delivery to neoplastic cells. HA also binds to several cell surface receptors to activate downstream cell signaling pathways associated with tumor proliferation and treatment resistance [14]. While ECM is thought to act as a barrier or impedance to effective chemotherapy, additional works suggest that it may also serve an integral structure role where its manipulation can revert PDA to a more aggressive biologic disease $[15,16]$.

Given the association between HA and tumor proliferation and chemotherapy resistance, preclinical work have explored the exploitation of HA as a potential target in the treatment of pancreas cancer. PEGylated hyaluronidase $\alpha$ (PEGPH20; Haylozyme Therapeutics) is a pegylated form of recombinant hyaluronidase, which lengthens the circulatory half-life $(>20 \mathrm{~h})$ to augment HA stromal degradation [17]. In preclinical animal studies, PEGPH20 normalized intra-tumor interstitial fluid pressures, enhanced intra-tumor chemotherapy delivery and tumoricidal activity [18]. Consistent with preclinical findings, observations from the HALO-109-101 and HALO-109-102 phase 1 trials, PEGPH20 increased plasma HA and tumor permeability, while decreasing tumor metabolic activity [19]. These results led to the randomized phase 2 trial, where patients with treatment naïve metastatic PDA received gemcitabine/nab-paclitaxel alone or in combination with PEGPH20 [20,21] (Table 1). Correlative work included baseline tumor HA level assessment, where HA levels were categorized as $\mathrm{HA}^{\text {low }}$ or $\mathrm{HA}^{\text {high }}$, which was defined by HA staining in the ECM as $<50 \%$ or $\geq 50 \%$ of tumor surface, respectively. In the first stage, 135 patients were randomized to receive gemcitabine/nab-paclitaxel alone or in combination with PEGPH20. Similar progression free survival (PFS) were observed between the two treatment arms (5.7 vs. 5.2 months, $\mathrm{HR}=0.69, p=0.11$ ) with an increase of thromboembolic events in the PEGPH20 arm (43\% vs. $25 \%$ [20]. In the 47 patients with HA $\mathrm{H}^{\text {high }}$ tumors, a significant improvement in PFS was observed in patients who received PEGPH20 (9.2 with PEGPH20 vs. 5.2 months, (HR, 0.45; 95\% CI, 0.17 to 1.22; $p=0.11$ ) [21]. Based on these results, in stage 2 of the trial, an additional 133 patients were randomized in a 2:1 fashion to receive gemcitabine/nab-paclitaxel in combination with PEGPH20 (PAG) or gemcitabine/nab-paclitaxel (AG) alone [22]. The two primary end points of the study were overall PFS (stages 1 and 2) and incidence of thromboembolic events in stage 2. The study's co-primary endpoints were met. $84(34 \%)$ of the 246 patients (with evaluable HA data) were identified as having HA ${ }^{\text {high }}$ tumors. A nominal but statistically significant improvement in PFS was seen in the PAG arm (6 vs. 5.3 months; HR 0.73; $p=0.049)$ in the protocol-defined efficacy evaluation population. The benefit was more pronounced in patients with HA ${ }^{\text {high }}$ tumors. Empiric prophylactic enoxaparin in the stage 2 of the study resulted in similar thromboembolic events between the two treatment arms (grade $\geq 3$ bleeding events, $4 \%$ in the AG arm vs. $8 \%$ PAG). These results led to HALO 301, an ongoing international randomized phase 3 trial, where patients with treatment naïve metastatic pancreatic adenocarcinoma with $\mathrm{HA}^{\text {high }}$ tumors are randomized in a 2:1 fashion to receive gemcitabine/nab-paclitaxel alone or in combination with PEGPH20 [23]. In contrast, S1313, a randomized phase 1b/2 trial that investigated FOLFIRINOX cytotoxic chemotherapy in combination with PEGPH20, was halted for futility based 
off the planned interim analysis [24]. The median overall survival in the FOLFIRINOX arm was 14.4 months vs. 7.7 months in the PEGPH20 arm, favoring the standard arm (HR 0.48; $p<0.01)$ [24]. These findings suggest a potential detrimental effect with the addition of PEGPH20 to FOLFIRINOX in patients with metastatic pancreas cancer. Preclinical studies provide insight to the observed S1313 results, as stroma depletion induced a more biologically aggressive form of pancreas cancer through VEGF dependence and enhanced immunosuppressive effects [15,16]. The unexpected S1313 results support that further work, including an evaluation to explain the observed findings, is needed prior to its development in future studies.

\subsection{Sonic Hedgehog Pathway (SHh)}

The SHh is a signaling pathway that transmits information to embryonic stem cells for cell differentiation and organogenesis. It is often inactive in adult tissues but also regulates adult stem cells and is involved in tissue preservation [25]. SHh overexpression is observed in various malignancies including PDA, where it is integral to the development of the paracrine signaling network that promotes desmoplasia formation $[25,26]$. Cancer associated fibroblasts, an integral component of the pancreas stroma, have also been noted to exhibit aberrant SHh activity [27].

In pancreas cancer mouse models, IPI-926, a SHh inhibitor, resulted in increased gemcitabine delivery by depleting stromal tissue and increasing vascular density [28]. Unfortunately, the promising preclinical activity did not translate to an improvement in patient outcomes in clinical trials. A phase 2 trial investigated gemcitabine monotherapy or in combination with IPI-926 in treatment naïve patients with metastatic PDA. Patients who received the combination of gemcitabine and IPI-926 experienced an inferior PFS and OS when compared to the control arm [29]. Another phase 2 randomized trial in patients with treatment naïve metastatic PDA also failed to demonstrate an improvement in PFS in patients that received the combination of gemcitabine with vismodegib, another SHh inhibitor [30]. The discordance seen between the preclinical and observed outcomes in clinical trials is unclear. More recent preclinical work suggests a potential detrimental effect from SHh inhibition, where increased IPI-296 exposure led to a more aggressive phenotype with undifferentiated histology, increased tumor cell proliferation and vascularity [15]. Similar results were also observed in preclinical studies with vismodegib [31]. Thus, it is feasible that certain components within the tumor microenvironment serve a protective purpose by restraining tumor growth and metastases. While the results from a completed phase 1 study with IPI-926 in combination with FOLFIRINOX in PDA have suggested potential clinical activity [32], the cumulative results observed with this group of agents suggest that the continued investigation of SHh inhibitors in pancreas cancer is unlikely to be yielding any meaningful efficacy. 
Table 1. Summary of ongoing or completed clinical trials investigating novel therapeutic agents in pancreatic ductal adenocarcinoma.

\begin{tabular}{|c|c|c|c|c|c|c|c|}
\hline Agent & Phase & Primary Endpoint & Treatment & Median PFS & Median OS & Comments & References/NCT * \\
\hline PEGPH20 & 2 & PFS & AG vs. PAG & $\begin{array}{l}5.7 \text { vs. } 5.2 \mathrm{mos}, \mathrm{HR} \\
\quad=0.69, p=0.11\end{array}$ & Pending & TE events ( $25 \%$ vs. $42 \%)$ & [20] \\
\hline PEGPH20 & 2 & PFS & AG vs. PAG & 9.2 vs. $5.2 \mathrm{mos}$ & Pending & TE events similar (PAG $14 \%$ vs. AG 10\%) & [22] \\
\hline PEGPH20 & 2 & PFS & FOLFIRINOX \pm PEGPH 20 & Pending & Pending & Halted early due to futility & NCT01959139 \\
\hline APX005M & $1 / 2$ & Safety, tolerance, PFS & PX005M + Gemcitabine/Nab-paclitaxel \pm Nivolumab & Pending & Pending & & NCT03214250 \\
\hline PF-04136309 & $1 \mathrm{~b} / 2$ & Safety, tolerance, PFS & PF-04136309 + Gemcitabine/Nab-paclitaxel & Pending & Pending & Treatment naïve & NCT02732938 \\
\hline Ibrutinib & $2 / 3$ & PFS & Ibrutinib + Gemcitabine/Nab-paclitaxel & Pending & Pending & & NCT02436668 \\
\hline Napabucasin & 3 & OS & Gemcitabine/Nab-paclitaxel \pm Napabucasin & Pending & Pending & & NCT02993731 \\
\hline Veliparib & 2 & OS & FOLFIRI \pm Veliparib & Pending & Pending & & NCT02890355 \\
\hline Olaparib & 3 & PFS & Olaparib vs. Placebo & Pending & Pending & $\begin{array}{l}\text { Germline } B R C A 1 / 2 \text { mutations; in pts whose have } \\
\text { not progressed on 1st line platinum chemo }\end{array}$ & NCT02184195 \\
\hline Rucaparib & 2 & ORR & Rucaparib (single arm) in $B R C A 1 / 2$ mutant patients & Not available & Not available & $\begin{array}{l}11 \% \text { ORR including } 1 \text { CR. Duration of confirmed } \\
\text { responses at } 36 \text { and } 49 \text { weeks }\end{array}$ & NCT02042378 \\
\hline Veliparib & 2 & ORR & Veliparib (single arm) in $B R C A 1 / 2$ mutant patients & $1.7 \mathrm{mos}$ & $3.1 \mathrm{mos}$ & No responses & [33] \\
\hline
\end{tabular}

AG—gemcitabine/nab-paclitaxel; PAG—PEGPH20 + gemcitabine/nab-paclitaxel; mos—months; TE—thromboembolic; PFS—progression free survival; OS—overall survival; ORR-objective response rate. ${ }^{*}$ http://clinicaltrials.gov. 


\section{The Promise and Challenge of Immune Targeting in PDA}

While immuno-oncologic agents have shown meaning clinical activity across several solid tumor malignancies, results from early clinical trials in PDA have been disappointing [34,35]. Its unique tumor microenvironment (TME) promotes immune evasion by suppressing tumor infiltrating lymphocyte activity (TILs) that contribute to dampening an anti-tumor immunogenic response [36]. Thus, strategies aimed at overcoming immunosuppression activity, which include agents that inhibit T-cell immune checkpoints with anti-PD1 or anti-CTLA-4 monoclonal antibodies, have not translated to clinical activity in pancreas cancer [34,37]. The identification of alternative targets within the TME may result in the identification and development of more effective immunotherapeutic agents in this disease.

\section{1. $C D 40$}

CD40 is a co-stimulatory protein present on antigen presenting cells (APCs), which CD4 ${ }^{+} \mathrm{T}$ helper cell activation requires the presence of $\mathrm{CD} 40$. Activated APCs are required to convert $\mathrm{CD}^{+} \mathrm{T}$ cells into cytotoxic effector $\mathrm{T}$ cells. Thus, through an indirect effect, CD40 activating monoclonal antibodies activate $\mathrm{CD} 8^{+} \mathrm{T}$ cells and potentially can reverse the immunosuppressive environment observed in pancreas cancer [38]. In early studies, the concomitant administration of CD40 agonist antibodies with gemcitabine resulted in clinical responses in PDA patients, where 4 of 21 patients experienced a partial response per RECIST criteria [39]. Moreover, correlative studies confirmed that CD40 activated macrophages induced the observed anti-tumor activity [39]. These results suggested that the observed immunogenic tumoricidal activity was derived from a CD40 dependent mechanism and potentially represent another treatment approach against PDA. In a phase 1 study, CP-8970,893, a CD40 agonist antibody, was given in combination with gemcitabine in patients with treatment naïve unresectable PDA [40]. Four of the 22 enrolled patients experienced a partial response, which demonstrated the potential of CD40 agonists as a treatment modality in pancreas cancer. An ongoing phase $1 / 2$ study is investigating APX005M, a CD40 agonistic monoclonal antibody with gemcitabine/nab-paclitaxel chemotherapy and the addition of Nivolumab, an anti-PD-1 monoclonal antibody [41].

\subsection{CCL2-CCR2}

The CCL2-CCR2 signaling axis has culminated enthusiasm as a novel therapeutic target in PDA. Chemokine CCL2 binding to CCR2, its cognate receptor, elicits the recruitment of monocytes and tumor-associated macrophages (TAMs) into the tumor microenvironment. These cells contribute to immunosuppression while inducing metastases, immune evasion and chemotherapy resistance. In preclinical studies, CCL2 production induced CCR2 $2^{+}$TAMs infiltration [42]. Coinciding clinical outcomes also revealed tumors that displayed high CCL2 expression/low CD* T-cell infiltrate was a poor prognostic factor. In PDA mouse models, CCR2 inhibition depleted inflammatory monocytes and macrophages, which resulted in enhanced chemotherapy efficacy and anti-tumor T-cell response while inhibiting tumor cell growth and metastasis [42,43]. A recently completed randomized phase 1B trial evaluated FOLFIRINOX in combination with PF-04136309, a CCR2 inhibitor, in patients with borderline resectable or locally advanced pancreatic adenocarcinoma. Patients who received the combination experienced a $48.5 \%$ response rate in comparison to the pre-specified expected response rate of $25 \%$ with FOLFIRINOX monotherapy [44]. Another randomized phase $1 \mathrm{~b} / 2$ clinical trial investigated the combination of gemcitabine/nab-paclitaxel with PF-04136309 has also been completed with pending results [45]

\subsection{Targeting Mast Cells}

The characteristic desmoplastic stroma in PDA is composed of inflammatory cells, which include mast cells that function as an integral component within the tumor microenvironment. Comprehensive assessment of human PDA samples revealed that mast cell infiltration was associated with poor prognostic factors that included higher tumor grade and worse overall survival [46], 
while increased mast cell concentration correlated with lymphatic and microvascular invasion and lymph node metastasis [47]. Ibrutinib, a Bruton's tyrosine kinase (BTK) inhibitor, inhibits mast cell degranulation and has been approved for the treatment of chronic lymphocytic leukemia and mantle cell lymphoma [48,49]. In PDA mouse models, Ibrutinib resulted in decreased tumor-associated inflammation and fibrosis, suggesting that PDA associated fibrosis is a mast cell dependent phenomena [50]. Ibrutinib also exhibited an anti-tumor effect through its inhibition of pancreatic cancer growth and increased gemcitabine cytotoxicity while enhancing $\mathrm{T}$ cell-dependent immune related tumoricidal activity [50,51]. These results lead to RESOLVE clinical trial, a randomized phase $2 / 3$ trial that is investigating gemcitabine/nab-paclitaxel alone or in combination with Ibrutinib, which has completed accrual. The primary endpoint of the study is PFS and the results will become available soon [52].

\section{Synthetic Lethality: Targeting Deficiencies in Homologous Recombination and DNA Repair}

In PDA, approximately $15 \%$ of patients harbor germline genomic alterations that increase susceptibility to the development of solid tumor malignancies [53]. Of these genes, alterations were observed most often in genes in the DNA mismatch repair (MMR) pathway, including BRCA1, BRCA2, and PALB2 [53]. In patients at risk, including individuals of Ashkenazi Jewish descent or those with a strong family history of pancreas cancer, the prevalence of $B R C A 1$ and $B R C A 2$ germline mutations has been reported in up to $19 \%[54,55]$.

$B R C A 1 / 2$ and PALB2 play an integral role in homologous recombination and DNA damage response [56]. Alternatively, PARP (poly (ADP)-ribose polymerase), a family of proteins that function to detect and initiate single-strand DNA break repair in the setting of BRCA dysfunction. PARP is a critical enzyme of cellular proliferation and mediates DNA repair of DNA single strand breaks and rescues tumor cells from DNA damage [57]. Thus, agents that inhibits PARP represents a rationale treatment strategy for patients with PDA who tumors harbor alterations in the MMR pathway. In the setting of deficient homologous repair and the inability to induce efficient DNA repair, tumors may have an enhanced sensitivity to DNA damaging cytotoxic chemotherapeutic agents that include platinum analogues and PARP inhibitors $[58,59]$. In several retrospective case series, patients with BRCA1/2-associated PDA achieved an improvement in objective response and OS when receiving platinum-containing chemotherapy regimens $[60,61]$. In the setting of homologous recombination deficiency, PARP inhibition can restrict the repair of these single-strand DNA breaks, resulting in DNA double-strand breaks and cell death. Several PARP inhibitors have been investigated across clinical trials in patients with BRCA mutant tumors with differing results. A phase 2 trial examined olaparib, an oral PARP inhibitor, in patients with treatment refractory germline $B R C A 1 / 2$ mutant tumors [62]. The primary endpoint of the study was response rate. In the 23 patients with PDA, $22 \%$ objective response was observed, with an additional $35 \%$ of patients having stable disease, consistent with findings seen in other solid tumor malignancies [62]. RUCAPANC, an open-label phase 2 trial investigated rucaparib, an oral PARP inhibitor, in previously treated patients with $B R C A 1 / 2$ mutant pancreatic adenocarcinoma [63]. Patients experienced a $11 \%$ response rate (in addition to one unconfirmed response), where the duration of confirmed responses was ongoing at 36 and 49 weeks [63]. In contrast to the two previously mentioned studies, in a phase 2 trial, no confirmed responses were observed with veliparib an oral PARP inhibitor, in individuals with treatment refractory BRCA1/2 or PALB2 mutant pancreatic adenocarcinoma [33]. The differences in observed anti-tumor activity from PARP inhibition is likely due to the differing efficacy of each PARP inhibitor rather than class activity of PARP inhibitors in homologous recombinant deficient PDA. From the enhanced tumoricidal activity observed with PARP inhibitors in the setting of existing DNA damage, PARP inhibition in combination with DNA damaging cytotoxic chemotherapy represents another strategy of interest. An ongoing randomized phase 2 study in patients with treatment refractory PDA is assessing FOLFIRI systemic chemotherapy alone or in combination with veliparib, with OS as its primary endpoint [64]. In conjunction with ongoing treatment strategies with PARP inhibitors, 
another area of interest is in their potential as maintenance therapy in patients whose tumors exhibit homologous recombinant deficiency. POLO (Olaparib in gBRCA Mutated Pancreatic Cancer Whose Disease Has Not Progressed on First Line Platinum-Based Chemotherapy), an ongoing randomized phase 3 study, is investigating olaparib in patients with metastatic $B R C A 1 / 2$ mutant pancreas cancer as a maintenance strategy following platinum based chemotherapy [65].

\section{Targeting Cancer Stem Cells}

Cancer stem cells (CSCs) are typified by their ability to produce tumor cells with varying phenotypes. Through activation of anti-apoptotic pathways and increased DNA repair mechanisms, CSCs are resistant to chemotherapy and radiotherapy. Furthermore, the exposure to conventional cytotoxic therapies can elicit "stemness" in cancer cells where CSCs are able to convert non-CSCs to CSC-like cells. CSC-like cells are able to persist after treatment and may serve as a mechanism for relapse after therapy. While uncertainty exists about true nature of CSCs and their role cancer proliferation, in PDA, CSCs have been identified as being CD44 ${ }^{+} \mathrm{CD}_{2} 4^{+} \mathrm{ESA}^{+}, \mathrm{CD} 133^{+} / \mathrm{CXCR}^{+}$, or $\mathrm{ALDH}^{\text {high }} \mathrm{CD} 44^{+} \mathrm{CD} 24^{-}$cells [66-68], where these cells are highly tumorigenic, promote metastatic spread, and are associated with poor survival. Since CSCs are resistant to traditional therapies including gemcitabine chemotherapy and radiotherapy [61,62], targeting the signaling pathways (Hedgehog, NANOG, STAT3) that drive cancer cell stemness represent a strategy against CSCs.

\subsection{Wnt/ $\beta$-Catenin}

Wnt pathway activation occurs in up to $65 \%$ of patients with PDA, and is important for CSC renewal, cell differentiation, tumorigenicity and epithelial-mesenchymal transition, which is in part responsible for resistance to conventional DNA damaging therapies (chemotherapy, radiotherapy). Wnt pathway is a key CSC signaling pathway that regulates CSC survival and proliferation. In a phase I trial of OMP-54F28 (OncoMed Pharmaceuticals, Redwood City, CA, USA) in patients with solid tumors, an Wnt pathway antagonist, 3 out of 26 patients experienced stable disease for $>6$ months [69]. In combination with gemcitabine in patients with treatment refractory PDA, a median PFS of 2 months was observed. Currently, other Wnt inhibitors that are under early investigation include CGX1321 [70] and a recently completed phase IB trial with Vantictumab in combination with gemcitabine/nab-paclitaxel in patients with previously untreated metastatic PDA [71].

\subsection{JAK/STAT}

JAK family receptor activation results in phosphorylation of STAT transcription factors. In PDA, JAK2/STAT3 activation contributes to cell cycle progression, anti-apoptosis and angiogenesis [72]. In KRAS mutant PDA mouse models, STAT3 inhibition resulted in tumor volume reduction and decreased cancer cell proliferation [73]. While early phase trials with JAK/STAT inhibitors showed promising results, in phase 3 trials, this did not translate to an improvement in patients' outcomes in PDA. JANUS-1, a randomized phase 3 trial, investigated the combination of Ruxolitinib, a janus kinase inhibitor selective for JAK1 and JAK2, with capecitabine in patients with treatment refractory metastatic PDA in patients with CRP (C-Reactive Protein) $>10$. Unfortunately, at the interim analysis, the study was discontinued for futility [74].

Inhibition of STAT3 transcription is another approach that has demonstrated promising results in targeting "stemness" in PDA. Napabucasin (BBI-608, Boston Biomedical Inc., Boston, MA, USA) an orally available first-in-class cancer stem cell inhibitor that appears to target and inhibit gene transcription induced by STAT3 and cancer cell stem cell properties, demonstrated the ability to inhibit relapse in PaCa-2 PDA xenograft mouse models [75]. This preliminary activity resulted in the investigation of napabucasin in a phase $1 \mathrm{~b} / 2$ trial in metastatic PDA. Patients received Napabucasin $240 \mathrm{mg}$ twice daily with weekly gemcitabine/nab-paclitaxel until disease progression or other criteria for discontinuation [76]. Among the 60 patients with measurable disease who were enrolled in the study, disease control, which was defined as complete response + partial response + stable disease, 
was observed in 55 patients (92\%) with two complete responses (3.3\%) and 26 partial responses $(43 \%)$ [76]. Treatment was well tolerated, where most treatment related adverse events were grade 1 and 2 gastrointestinal events. Grade 3 adverse events were observed in 12 patients, primarily due to fatigue (8) and gastrointestinal symptoms (3) [76]. Based on these results, CANSTEM 111p [77], an ongoing randomized phase III trial is investigating gemcitabine/nab-paclitaxel monotherapy or with napabucasin to confirm the clinical activity observed in the phase $1 \mathrm{~b} / 2$ study.

\section{Conclusions and Future Directions}

At this present time, the treatment of pancreatic adenocarcinoma remains a challenge, with limited treatment options that provide modest improvements in patient outcomes. Despite advances that include the recent molecular characterization of PDA, and an increased understanding of the TME and its role in chemotherapy resistance, direct usage of the knowledge has not translated into an improvement in patient outcomes, where treatment options remain limited to cytotoxic chemotherapy regimens (FOLFIRINOX, gemcitabine/nab-paclitaxel, Onyvide). Nevertheless, further advances are needed, and several promising treatment strategies are being investigated and outlined above. These efforts include utilizing tumor genomic profiling to identify the subset of patients with deficiencies in homologous recombination and DNA repair that will likely benefit from novel agents aimed at exploiting these defects (e.g., PARP inhibitors, platinum chemotherapy agents). Furthermore, while several studies have not demonstrated success in targeting the tumor stroma, further refinement and an ongoing phase 3 trial will inform us if this remains a relevant treatment strategy in PDA. Additional alternative therapeutic approaches include novel agents aimed at targeting cancer stem cell properties, immune sensitization, and the tumor microenvironment. These innovative approaches have reignited optimism and enthusiasm to spur investigation in both early- and later-phase clinical trials that hopefully will result in improving patient outcomes in this terrible disease.

Author Contributions: D.H.A. contributed to the design, manuscript preparation and writing. R.K.R. contributed to manuscript preparation and writing. T.B.-S. contributed to the design, manuscript preparation and writing.

Funding: This research received no external funding.

Conflicts of Interest: The authors declare no conflict of interest.

\section{References}

1. Howlader, N.; Noone, A.M.; Krapcho, M.; Miller, D.; Bishop, K.; Kosary, C.L.; Yu, M.; Ruhl, J.; Tatalovich, Z.; Mariotto, A.; et al. Seer Cancer Statistics Review, 1975-2014; National Cancer Institute: Bethesda, MD, USA, Based on November 2016 Seer Data Submission, Posted to the Seer Web Site; April 2017. Available online: https: / / seer.Cancer.Gov/statfacts/html/pancreas.Html (accessed on 8 June 2018).

2. Siegel, R.L.; Miller, K.D.; Jemal, A. Cancer statistics, 2016. CA-A Cancer J. Clin. 2016, 66, 7-30. [CrossRef] [PubMed]

3. Conroy, T.; Desseigne, F.; Ychou, M.; Bouche, O.; Guimbaud, R.; Becouarn, Y.; Adenis, A.; Raoul, J.L.; Gourgou-Bourgade, S.; de la Fouchardiere, C.; et al. Folfirinox versus gemcitabine for metastatic pancreatic cancer. N. Engl. J. Med. 2011, 364, 1817-1825. [CrossRef] [PubMed]

4. Von Hoff, D.D.; Ervin, T.; Arena, F.P.; Chiorean, E.G.; Infante, J.; Moore, M.; Seay, T.; Tjulandin, S.A.; Ma, W.W.; Saleh, M.N.; et al. Increased survival in pancreatic cancer with nab-paclitaxel plus gemcitabine. N. Engl. J. Med. 2013, 369, 1691-1703. [CrossRef] [PubMed]

5. Wang-Gillam, A.; Li, C.P.; Bodoky, G.; Dean, A.; Shan, Y.S.; Jameson, G.; Macarulla, T.; Lee, K.H.; Cunningham, D.; Blanc, J.F.; et al. Nanoliposomal irinotecan with fluorouracil and folinic acid in metastatic pancreatic cancer after previous gemcitabine-based therapy (napoli-1): A global, randomised, open-label, phase 3 trial. Lancet 2016, 387, 545-557. [CrossRef]

6. Chu, G.C.; Kimmelman, A.C.; Hezel, A.F.; DePinho, R.A. Stromal biology of pancreatic cancer. J. Cell. Biochem. 2007, 101, 887-907. [CrossRef] [PubMed] 
7. Phillips, P.A.; McCarroll, J.A.; Park, S.; Wu, M.J.; Pirola, R.; Korsten, M.; Wilson, J.S.; Apte, M.V. Rat pancreatic stellate cells secrete matrix metalloproteinases: Implications for extracellular matrix turnover. Gut 2003, 52, 275-282. [CrossRef] [PubMed]

8. Shek, F.W.; Benyon, R.C.; Walker, F.M.; McCrudden, P.R.; Pender, S.L.; Williams, E.J.; Johnson, P.A.; Johnson, C.D.; Bateman, A.C.; Fine, D.R.; et al. Expression of transforming growth factor-beta 1 by pancreatic stellate cells and its implications for matrix secretion and turnover in chronic pancreatitis. Am. J. Pathol. 2002, 160, 1787-1798. [CrossRef]

9. Masamune, A.; Shimosegawa, T. Signal transduction in pancreatic stellate cells. J. Gastroenterol. 2009, 44, 249-260. [CrossRef] [PubMed]

10. Mantoni, T.S.; Lunardi, S.; Al-Assar, O.; Masamune, A.; Brunner, T.B. Pancreatic stellate cells radioprotect pancreatic cancer cells through beta1-integrin signaling. Cancer Res. 2011, 71, 3453-3458. [CrossRef] [PubMed]

11. Erkan, M.; Reiser-Erkan, C.; Michalski, C.W.; Deucker, S.; Sauliunaite, D.; Streit, S.; Esposito, I.; Friess, H.; Kleeff, J. Cancer-stellate cell interactions perpetuate the hypoxia-fibrosis cycle in pancreatic ductal adenocarcinoma. Neoplasia 2009, 11, 497-508. [CrossRef] [PubMed]

12. Hingorani, S.R.; Petricoin, E.F.; Maitra, A.; Rajapakse, V.; King, C.; Jacobetz, M.A.; Ross, S.; Conrads, T.P.; Veenstra, T.D.; Hitt, B.A.; et al. Preinvasive and invasive ductal pancreatic cancer and its early detection in the mouse. Cancer Cell 2003, 4, 437-450. [CrossRef]

13. Mace, T.A.; Ameen, Z.; Collins, A.; Wojcik, S.; Mair, M.; Young, G.S.; Fuchs, J.R.; Eubank, T.D.; Frankel, W.L.; Bekaii-Saab, T.; et al. Pancreatic cancer-associated stellate cells promote differentiation of myeloid-derived suppressor cells in a stat3-dependent manner. Cancer Res. 2013, 73, 3007-3018. [CrossRef] [PubMed]

14. Kultti, A.; Li, X.; Jiang, P.; Thompson, C.B.; Frost, G.I.; Shepard, H.M. Therapeutic targeting of hyaluronan in the tumor stroma. Cancers 2012, 4, 873-903. [CrossRef] [PubMed]

15. Rhim, A.D.; Oberstein, P.E.; Thomas, D.H.; Mirek, E.T.; Palermo, C.F.; Sastra, S.A.; Dekleva, E.N.; Saunders, T.; Becerra, C.P.; Tattersall, I.W.; et al. Stromal elements act to restrain, rather than support, pancreatic ductal adenocarcinoma. Cancer Cell 2014, 25, 735-747. [CrossRef] [PubMed]

16. Ozdemir, B.C.; Pentcheva-Hoang, T.; Carstens, J.L.; Zheng, X.; Wu, C.C.; Simpson, T.R.; Laklai, H.; Sugimoto, H.; Kahlert, C.; Novitskiy, S.V.; et al. Depletion of carcinoma-associated fibroblasts and fibrosis induces immunosuppression and accelerates pancreas cancer with reduced survival. Cancer Cell 2014, 25, 719-734. [CrossRef] [PubMed]

17. Thompson, C.B.; Shepard, H.M.; O'Connor, P.M.; Kadhim, S.; Jiang, P.; Osgood, R.J.; Bookbinder, L.H.; Li, X.; Sugarman, B.J.; Connor, R.J.; et al. Enzymatic depletion of tumor hyaluronan induces antitumor responses in preclinical animal models. Mol. Cancer Ther. 2010, 9, 3052-3064. [CrossRef] [PubMed]

18. Provenzano, P.P.; Cuevas, C.; Chang, A.E.; Goel, V.K.; Von Hoff, D.D.; Hingorani, S.R. Enzymatic targeting of the stroma ablates physical barriers to treatment of pancreatic ductal adenocarcinoma. Cancer Cell 2012, 21, 418-429. [CrossRef] [PubMed]

19. Infante, J.R.; Korn, R.L.; Rosen, L.S.; LoRusso, P.; Dychter, S.S.; Zhu, J.; Maneval, D.C.; Jiang, P.; Shepard, H.M.; Frost, G.; et al. Phase 1 trials of pegylated recombinant human hyaluronidase $\mathrm{PH} 20$ in patients with advanced solid tumours. Br. J. Cancer 2017, 118, 153. [CrossRef] [PubMed]

20. Bullock, A.J.; Hingorani, S.R.; Wu, X.W.; Jiang, P.; Chondros, D.; Khelifa, S.; Aldrich, C.; Pu, J.; Hendifar, A.E. Final analysis of stage 1 data from a randomized phase ii study of pegph20 plus nab-paclitaxel/gemcitabine in stage IV previously untreated pancreatic cancer patients (PTS), utilizing ventana companion diagnostic assay. J. Clin. Oncol. 2016, 34, 4104-4104.

21. Hingorani, S.R.; Zheng, L.; Bullock, A.J.; Seery, T.E.; Harris, W.P.; Sigal, D.S.; Braiteh, F.; Ritch, P.S.; Zalupski, M.M.; Bahary, N.; et al. Halo 202: Randomized phase II study of pegph20 plus nab-paclitaxel/gemcitabine versus nab-paclitaxel/gemcitabine in patients with untreated, metastatic pancreatic ductal adenocarcinoma. J. Clin. Oncol. 2018, 36, 359-366. [CrossRef] [PubMed]

22. Hingorani, S.R.; Bullock, A.J.; Seery, T.E.; Zheng, L.; Sigal, D.; Ritch, P.S.; Braiteh, F.S.; Zalupski, M.; Bahary, N.; Harris, W.P.; et al. Randomized phase II study of pegph20 plus nab-paclitaxel/gemcitabine (PAG) vs. ag in patients (pts) with untreated, metastatic pancreatic ductal adenocarcinoma (MPDA). J. Clin. Oncol. 2017, 35, 4008-4008. 
23. ClinicalTrials.gov. Available online: https://clinicaltrials.gov/ct2/show/NCT02715804 (accessed on 8 June 2018).

24. Ramanathan, R.K.; McDonough, S.; Philip, P.A.; Hingorani, S.R.; Lacy, J.; Kortmansky, J.S.; Thumar, J.R.; Chiorean, E.G.; Shields, A.F.; Behl, D.; et al. A phase IB/II randomized study of mfolfirinox (mffox) + pegylated recombinant human hyaluronidase (pegph20) versus mffox alone in patients with good performance status metastatic pancreatic adenocarcinoma (MPC): Swog s1313 (NCT \#01959139). J. Clin. Oncol. 2018, 36, 208.

25. Tian, H.; Callahan, C.A.; DuPree, K.J.; Darbonne, W.C.; Ahn, C.P.; Scales, S.J.; de Sauvage, F.J. Hedgehog signaling is restricted to the stromal compartment during pancreatic carcinogenesis. Proc. Natl. Acad. Sci. USA 2009, 106, 4254-4259. [CrossRef] [PubMed]

26. Bailey, J.M.; Swanson, B.J.; Hamada, T.; Eggers, J.P.; Singh, P.K.; Caffery, T.; Ouellette, M.M.; Hollingsworth, M.A. Sonic hedgehog promotes desmoplasia in pancreatic cancer. Clin. Cancer Res. 2008, 14, 5995-6004. [CrossRef] [PubMed]

27. Walter, K.; Omura, N.; Hong, S.M.; Griffith, M.; Vincent, A.; Borges, M.; Goggins, M. Overexpression of smoothened activates the sonic hedgehog signaling pathway in pancreatic cancer-associated fibroblasts. Clin. Cancer Res. 2010, 16, 1781-1789. [CrossRef] [PubMed]

28. Olive, K.P.; Jacobetz, M.A.; Davidson, C.J.; Gopinathan, A.; McIntyre, D.; Honess, D.; Madhu, B.; Goldgraben, M.A.; Caldwell, M.E.; Allard, D.; et al. Inhibition of hedgehog signaling enhances delivery of chemotherapy in a mouse model of pancreatic cancer. Science 2009, 324, 1457-1461. [CrossRef] [PubMed]

29. Ahn, D.H.; Bekaii-Saab, T. Biliary cancer: Intrahepatic cholangiocarcinoma vs. Extrahepatic cholangiocarcinoma vs. Gallbladder cancers: Classification and therapeutic implications. J. Gastrointest. Oncol. 2017, 8, 293-301. [CrossRef] [PubMed]

30. Catenacci, D.V.; Junttila, M.R.; Karrison, T.; Bahary, N.; Horiba, M.N.; Nattam, S.R.; Marsh, R.; Wallace, J.; Kozloff, M.; Rajdev, L.; et al. Randomized phase IB/II study of gemcitabine plus placebo or vismodegib, a hedgehog pathway inhibitor, in patients with metastatic pancreatic cancer. J. Clin. Oncol. Off. J. Am. Soc. Clin. Oncol. 2015, 33, 4284-4292. [CrossRef] [PubMed]

31. Lee, J.J.; Perera, R.M.; Wang, H.; Wu, D.C.; Liu, X.S.; Han, S.; Fitamant, J.; Jones, P.D.; Ghanta, K.S.; Kawano, S.; et al. Stromal response to hedgehog signaling restrains pancreatic cancer progression. Proc. Natl. Acad. Sci. USA 2014, 111, E3091-3100. [CrossRef] [PubMed]

32. Ko, A.H.; LoConte, N.; Tempero, M.A.; Walker, E.J.; Kate Kelley, R.; Lewis, S.; Chang, W.C.; Kantoff, E.; Vannier, M.W.; Catenacci, D.V.; et al. A phase I study of folfirinox plus IPI-926, a hedgehog pathway inhibitor, for advanced pancreatic adenocarcinoma. Pancreas 2016, 45, 370-375. [CrossRef] [PubMed]

33. Lowery, M.A.; Kelsen, D.P.; Capanu, M.; Smith, S.C.; Lee, J.W.; Stadler, Z.K.; Moore, M.J.; Kindler, H.L.; Golan, T.; Segal, A.; et al. Phase II trial of veliparib in patients with previously treated BRCA-mutated pancreas ductal adenocarcinoma. Eur. J. Cancer 2018, 89, 19-26. [CrossRef] [PubMed]

34. Royal, R.E.; Levy, C.; Turner, K.; Mathur, A.; Hughes, M.; Kammula, U.S.; Sherry, R.M.; Topalian, S.L.; Yang, J.C.; Lowy, I.; et al. Phase 2 trial of single agent ipilimumab (anti-CTLA-4) for locally advanced or metastatic pancreatic adenocarcinoma. J. Immunother. 2010, 33, 828-833. [CrossRef] [PubMed]

35. Brahmer, J.R.; Tykodi, S.S.; Chow, L.Q.; Hwu, W.J.; Topalian, S.L.; Hwu, P.; Drake, C.G.; Camacho, L.H.; Kauh, J.; Odunsi, K.; et al. Safety and activity of anti-PD-L1 antibody in patients with advanced cancer. N. Engl. J. Med. 2012, 366, 2455-2465. [CrossRef] [PubMed]

36. Zou, W. Immunosuppressive networks in the tumour environment and their therapeutic relevance. Nat. Rev. Cancer 2005, 5, 263-274. [CrossRef] [PubMed]

37. Topalian, S.L.; Hodi, F.S.; Brahmer, J.R.; Gettinger, S.N.; Smith, D.C.; McDermott, D.F.; Powderly, J.D.; Carvajal, R.D.; Sosman, J.A.; Atkins, M.B.; et al. Safety, activity, and immune correlates of anti-PD-1 antibody in cancer. N. Engl. J. Med. 2012, 366, 2443-2454. [CrossRef] [PubMed]

38. Byrne, K.T.; Vonderheide, R.H. Cd40 stimulation obviates innate sensors and drives t cell immunity in cancer. Cell Rep. 2016, 15, 2719-2732. [CrossRef] [PubMed]

39. Beatty, G.L.; Chiorean, E.G.; Fishman, M.P.; Saboury, B.; Teitelbaum, U.R.; Sun, W.; Huhn, R.D.; Song, W.; Li, D.; Sharp, L.L.; et al. CD40 agonists alter tumor stroma and show efficacy against pancreatic carcinoma in mice and humans. Science 2011, 331, 1612-1616. [CrossRef] [PubMed] 
40. Beatty, G.L.; Torigian, D.A.; Chiorean, E.G.; Saboury, B.; Brothers, A.; Alavi, A.; Troxel, A.B.; Sun, W.; Teitelbaum, U.R.; Vonderheide, R.H.; et al. A phase I study of an agonist CD40 monoclonal antibody (cp-870,893) in combination with gemcitabine in patients with advanced pancreatic ductal adenocarcinoma. Clin. Cancer Res. 2013, 19, 6286-6295. [CrossRef] [PubMed]

41. ClinicalTrials.gov. Available online: https://clinicaltrials.gov/ct2/show/NCT03214250 (accessed on 8 June 2018).

42. Sanford, D.E.; Belt, B.A.; Panni, R.Z.; Mayer, A.; Deshpande, A.D.; Carpenter, D.; Mitchem, J.B.; Plambeck-Suess, S.M.; Worley, L.A.; Goetz, B.D.; et al. Inflammatory monocyte mobilization decreases patient survival in pancreatic cancer: A role for targeting the CCL2/CCR2 axis. Clin. Cancer Res. 2013, 19, 3404-3415. [CrossRef] [PubMed]

43. Mitchem, J.B.; Brennan, D.J.; Knolhoff, B.L.; Belt, B.A.; Zhu, Y.; Sanford, D.E.; Belaygorod, L.; Carpenter, D.; Collins, L.; Piwnica-Worms, D.; et al. Targeting tumor-infiltrating macrophages decreases tumor-initiating cells, relieves immunosuppression, and improves chemotherapeutic responses. Cancer Res. 2013, 73, 1128-1141. [CrossRef] [PubMed]

44. Nywening, T.M.; Wang-Gillam, A.; Sanford, D.E.; Belt, B.A.; Panni, R.Z.; Cusworth, B.M.; Toriola, A.T.; Nieman, R.K.; Worley, L.A.; Yano, M.; et al. Targeting tumour-associated macrophages with ccr2 inhibition in combination with folfirinox in patients with borderline resectable and locally advanced pancreatic cancer: A single-centre, open-label, dose-finding, non-randomised, phase 1b trial. Lancet Oncol. 2016, 17, 651-662. [CrossRef]

45. ClinicalTrials.gov. Available online: https://clinicaltrials.gov/ct2/show/NCT02732938 (accessed on 8 June 2018).

46. Strouch, M.J.; Cheon, E.C.; Salabat, M.R.; Krantz, S.B.; Gounaris, E.; Melstrom, L.G.; Dangi-Garimella, S.; Wang, E.; Munshi, H.G.; Khazaie, K.; et al. Crosstalk between mast cells and pancreatic cancer cells contributes to pancreatic tumor progression. Clin. Cancer Res. 2010, 16, 2257-2265. [CrossRef] [PubMed]

47. Cai, S.W.; Yang, S.Z.; Gao, J.; Pan, K.; Chen, J.Y.; Wang, Y.L.; Wei, L.X.; Dong, J.H. Prognostic significance of mast cell count following curative resection for pancreatic ductal adenocarcinoma. Surgery 2011, 149, 576-584. [CrossRef] [PubMed]

48. Byrd, J.C.; Furman, R.R.; Coutre, S.E.; Flinn, I.W.; Burger, J.A.; Blum, K.A.; Grant, B.; Sharman, J.P.; Coleman, M.; Wierda, W.G.; et al. Targeting BTK with ibrutinib in relapsed chronic lymphocytic leukemia. N. Engl. J. Med. 2013, 369, 32-42. [CrossRef] [PubMed]

49. Chang, B.Y.; Huang, M.M.; Francesco, M.; Chen, J.; Sokolove, J.; Magadala, P.; Robinson, W.H.; Buggy, J.J. The bruton tyrosine kinase inhibitor pci-32765 ameliorates autoimmune arthritis by inhibition of multiple effector cells. Arthritis Res. Ther. 2011, 13, R115. [CrossRef] [PubMed]

50. Masso-Valles, D.; Jauset, T.; Serrano, E.; Sodir, N.M.; Pedersen, K.; Affara, N.I.; Whitfield, J.R.; Beaulieu, M.E.; Evan, G.I.; Elias, L.; et al. Ibrutinib exerts potent antifibrotic and antitumor activities in mouse models of pancreatic adenocarcinoma. Cancer Res. 2015, 75, 1675-1681. [CrossRef] [PubMed]

51. Gunderson, A.J.; Kaneda, M.M.; Tsujikawa, T.; Nguyen, A.V.; Affara, N.I.; Ruffell, B.; Gorjestani, S.; Liudahl, S.M.; Truitt, M.; Olson, P.; et al. Bruton tyrosine kinase-dependent immune cell cross-talk drives pancreas cancer. Cancer Discov. 2016, 6, 270-285. [CrossRef] [PubMed]

52. ClinicalTrials.gov. Available online: https://clinicaltrials.gov/ct2/show/NCT02436668 (accessed on 8 June 2018).

53. Salo-Mullen, E.E.; O’Reilly, E.M.; Kelsen, D.P.; Ashraf, A.M.; Lowery, M.A.; Yu, K.H.; Reidy, D.L.; Epstein, A.S.; Lincoln, A.; Saldia, A.; et al. Identification of germline genetic mutations in patients with pancreatic cancer. Cancer 2015, 121, 4382-4388. [CrossRef] [PubMed]

54. Stadler, Z.K.; Salo-Mullen, E.; Patil, S.M.; Pietanza, M.C.; Vijai, J.; Saloustros, E.; Hansen, N.A.; Kauff, N.D.; Kurtz, R.C.; Kelsen, D.P.; et al. Prevalence of BRCA1 and BRCA2 mutations in Ashkenazi Jewish families with breast and pancreatic cancer. Cancer 2012, 118, 493-499. [CrossRef] [PubMed]

55. Murphy, K.M.; Brune, K.A.; Griffin, C.; Sollenberger, J.E.; Petersen, G.M.; Bansal, R.; Hruban, R.H.; Kern, S.E. Evaluation of candidate genes MAP2K4, MADH4, ACVR1B, and BRCA2 in familial pancreatic cancer: Deleterious brca2 mutations in 17\%. Cancer Res. 2002, 62, 3789-3793. [PubMed]

56. Turner, N.; Tutt, A.; Ashworth, A. Hallmarks of 'brcaness' in sporadic cancers. Nat. Rev. Cancer 2004, 4, 814-819. [CrossRef] [PubMed] 
57. Helleday, T.; Bryant, H.E.; Schultz, N. Poly(ADP-ribose) polymerase (PARP-1) in homologous recombination and as a target for cancer therapy. Cell Cycle 2005, 4, 1176-1178. [CrossRef] [PubMed]

58. Lee, J.M.; Ledermann, J.A.; Kohn, E.C. PARP inhibitors for brca1/2 mutation-associated and BRCA-like malignancies. Ann. Oncol. 2014, 25, 32-40. [CrossRef] [PubMed]

59. Yap, T.A.; Sandhu, S.K.; Carden, C.P.; de Bono, J.S. Poly(adp-ribose) polymerase (PARP) inhibitors: Exploiting a synthetic lethal strategy in the clinic. CA-A Cancer J. Clin. 2011, 61, 31-49. [CrossRef] [PubMed]

60. Golan, T.; Kanji, Z.S.; Epelbaum, R.; Devaud, N.; Dagan, E.; Holter, S.; Aderka, D.; Paluch-Shimon, S.; Kaufman, B.; Gershoni-Baruch, R.; et al. Overall survival and clinical characteristics of pancreatic cancer in brca mutation carriers. Br. J. Cancer 2014, 111, 1132-1138. [CrossRef] [PubMed]

61. Lowery, M.A.; Kelsen, D.P.; Stadler, Z.K.; Yu, K.H.; Janjigian, Y.Y.; Ludwig, E.; D'Adamo, D.R.; Salo-Mullen, E.; Robson, M.E.; Allen, P.J.; et al. An emerging entity: Pancreatic adenocarcinoma associated with a known BRCA mutation: Clinical descriptors, treatment implications, and future directions. Oncologist 2011, 16, 1397-1402. [CrossRef] [PubMed]

62. Kaufman, B.; Shapira-Frommer, R.; Schmutzler, R.K.; Audeh, M.W.; Friedlander, M.; Balmana, J.; Mitchell, G.; Fried, G.; Stemmer, S.M.; Hubert, A.; et al. Olaparib monotherapy in patients with advanced cancer and a germline brca1/2 mutation. J. Clin. Oncol. 2015, 33, 244-250. [CrossRef] [PubMed]

63. Domchek, S.M.; Hendifar, A.E.; McWilliams, R.R.; Geva, R.; Epelbaum, R.; Biankin, A.; Vonderheide, R.H.; Wolff, R.A.; Alberts, S.R.; Giordano, H.; et al. Rucapanc: An open-label, phase 2 trial of the PARP inhibitor rucaparib in patients (PTS) with pancreatic cancer (PC) and a known deleterious Germline or somatic BRCA mutation. J. Clin. Oncol. 2016, 34, 4110-4110.

64. ClinicalTrials.gov. Available online: https://clinicaltrials.gov/ct2/show/NCT02890355 (accessed on 8 June 2018).

65. ClinicalTrials.gov. Available online: https://clinicaltrials.gov/ct2/show/NCT02184195 (accessed on 8 June 2018).

66. Hutcheson, J.; Balaji, U.; Porembka, M.R.; Wachsmann, M.B.; McCue, P.A.; Knudsen, E.S.; Witkiewicz, A.K. Immunologic and metabolic features of pancreatic ductal adenocarcinoma define prognostic subtypes of disease. Clin. Cancer Res. 2016, 22, 3606-3617. [CrossRef] [PubMed]

67. Li, C.; Heidt, D.G.; Dalerba, P.; Burant, C.F.; Zhang, L.; Adsay, V.; Wicha, M.; Clarke, M.F.; Simeone, D.M. Identification of pancreatic cancer stem cells. Cancer Res. 2007, 67, 1030-1037. [CrossRef] [PubMed]

68. Kim, M.P.; Fleming, J.B.; Wang, H.; Abbruzzese, J.L.; Choi, W.; Kopetz, S.; McConkey, D.J.; Evans, D.B.; Gallick, G.E. Aldh activity selectively defines an enhanced tumor-initiating cell population relative to CD133 expression in human pancreatic adenocarcinoma. PLoS ONE 2011, 6, e20636. [CrossRef] [PubMed]

69. Jimeno, A.; Gordon, M.; Chugh, R.; Messersmith, W.; Mendelson, D.; Dupont, J.; Stagg, R.; Kapoun, A.M.; $\mathrm{Xu}$, L.; Uttamsingh, S.; et al. A first-in-human phase i study of the anticancer stem cell agent ipafricept (OMP-54f28), a decoy receptor for wnt ligands, in patients with advanced solid tumors. Clin. Cancer Res. 2017, 23, 7490-7497. [CrossRef] [PubMed]

70. ClinicalTrials.gov. Available online: https://clinicaltrials.gov/ct2/show/NCT02675946 (accessed on 8 June 2018).

71. ClinicalTrials.gov. Available online: https://clinicaltrials.gov/ct2/show/NCT02005315 (accessed on 8 June 2018).

72. Yu, J.H.; Kim, H. Role of janus kinase/signal transducers and activators of transcription in the pathogenesis of pancreatitis and pancreatic cancer. Gut Liver 2012, 6, 417-422. [CrossRef] [PubMed]

73. Corcoran, R.B.; Contino, G.; Deshpande, V.; Tzatsos, A.; Conrad, C.; Benes, C.H.; Levy, D.E.; Settleman, J.; Engelman, J.A.; Bardeesy, N. Stat3 plays a critical role in kras-induced pancreatic tumorigenesis. Cancer Res. 2011, 71, 5020-5029. [CrossRef] [PubMed]

74. Hurwitz, H.; Cutsem, E.V.; Bendell, J.C.; Hidalgo, M.; Li, C.-P.; Garrido, M.; Macarulla, T.M.; Sahai, V.; Sama, A.R.; Greeno, E.; et al. Two randomized, placebo-controlled phase 3 studies of ruxolitinib (RUX) + capecitabine (C) in patients (PTS) with advanced/metastatic pancreatic cancer (MPC) after failure/intolerance of first-line chemotherapy: Janus 1 (j1) and janus 2 (j2). J. Clin. Oncol. 2017, 35, 343-343. [CrossRef]

75. Li, Y.; Rogoff, H.A.; Keates, S.; Gao, Y.; Murikipudi, S.; Mikule, K.; Leggett, D.; Li, W.; Pardee, A.B.; Li, C.J. Suppression of cancer relapse and metastasis by inhibiting cancer stemness. Proc. Natl. Acad. Sci. USA 2015, 112, 1839-1844. [CrossRef] [PubMed] 
76. Bekaii-Saab, T.S.; Starodub, A.; El-Rayes, B.F.; O’Neil, B.H.; Shahda, S.; Ciombor, K.K.; Noonan, A.M.; Hanna, W.T.; Sehdev, A.; Shaib, W.L.; et al. A phase IB/II study of cancer stemness inhibitor napabucasin (BBI-608) in combination with gemcitabine (GEM) and nab-paclitaxel (NABPTX) in metastatic pancreatic adenocarcinoma (MPDAC) patients (PTS). J. Clin. Oncol. 2017, 35, 4106-4106.

77. ClinicalTrials.gov. Available online: https://clinicaltrials.gov/ct2/show/NCT02231723 (accessed on 8 June 2018).

2018 by the authors. Licensee MDPI, Basel, Switzerland. This article is an open access article distributed under the terms and conditions of the Creative Commons Attribution (CC BY) license (http://creativecommons.org/licenses/by/4.0/). 